\title{
Mathematical modeling of primary sludge anaerobic hydrolysis
}

\author{
Efstathiou E. ${ }^{1}$, Mamais D. ${ }^{2^{*}}$, Tsourtis S. ${ }^{2}$ and Tridimas P. ${ }^{2}$ \\ ${ }^{1}$ Athens Water and Sewerage Company S.A (E.Y.D.A.P.), Oropou 156, 11146, Galatsi, Athens, Greece \\ 2Sanitary Engineering Laboratory, Department of Water Resources and Environmental Engineering, School of Civil Engineering, \\ National Technical University of Athens, Iroon Polytechniou 9, Zografou 157 80, Athens, Greece \\ Received: 10/05/2017, Accepted: 15/05/2019, Available online: 15/05/2019 \\ *to whom all correspondence should be addressed: e-mail: mamais@central.ntua.gr \\ https://doi.org/10.30955/gnj.002343
}

\section{Abstract}

The aim of this work was the application and evaluation of a mathematical model for the simulation of anaerobic hydrolysis and acid production processes. For the description of the processes involved, the Anaerobic Digestion Model ADM1 was employed. The ADM1 implementation in prefermenters is relatively easy, but the estimation of its components concentrations, kinetic parameters and stoichiometric coefficients, remains a problem to be solved. This study provides useful results for the ADM1 implementation in acid digesters design and operation. Model calibration and verification was performed using experimental data from two bench scale acid digesters operating at different temperatures $(12,20$, 27 and $34{ }^{\circ} \mathrm{C}$ ) and retention times (1,2, 4 and 6 days). Model sensitivity analysis illustrated that the values of $\mathrm{pH}$, disintegration kinetic parameter and aceticlastic methanogenesis specific rate, as well as biomass and inert soluble COD concentrations in the primary sludge exert a significant influence on soluble COD production. Model parameters (disintegration and hydrolysis kinetic parameters and specific rate of methane production) as well as the temperature dependency of these parameters are given in this paper.

Keywords: Anaerobic sludge hydrolysis, mathematical modelling, prefermenter, temperature effect.

\section{Introduction}

Anaerobic biodegradation processes may be divided to at least three stages: hydrolysis, acid/acetogenesis and methanogenesis. These processes are normally catalyzed by intracellular or extracellular enzymes and act on the pool of available organic material. Disintegration of composites (such as dead biomass) to particulate constituents and their subsequent enzymatic hydrolysis to soluble monomers are extracellural processes. Digestion of soluble materials mediated by organisms is intracellular process and results in biomass growth and decay (IWA, 2002).

In the hydrolysis phase, the volatile suspended solids, mainly consisting of proteins (approx. 30\%), carbohydrates (approx. 40\%) and lipids (approx. 30\%), are hydrolyzed by means of extracellular enzymes to aminoacids, sugars and long chain fatty acids (LCFA) respectively. In acidogenesis phase the products from the hydrolysis are fermented into volatile acids and in subsequent acetogenesis phase LCFA as well as volatile fatty acids (VFA) except acetate are decomposed through $\beta$-oxidation (Brinch et al., 1994). Finally, methane is produced in the last phase by means of two groups of methanogen bacteria: a) hydrogenotrophic methanogens, and b) aceticlastic or acetotrophic bacteria.

Acid phase digestion may be employed to produce soluble organic carbon suitable for use as energy substrate for two-stage biological denitrification or biological phosphorus removal (BNR), (Pitman et al., 1992). Maximum production of soluble organic carbon can be achieved only when methane production has been effectively suppressed. The minimum cell residence time for methane production from lipids and volatile acids at mesophilic temperatures and normal $\mathrm{pH}$ values of 6.8 to 7.5 is approximately 2.5 to 4 days. However some methane is produced at much shorter detention times due to utilization of hydrogen produced during fermentation of carbohydrates and proteins to volatile acids. Minimum cell residence time for hydrogen utilizing bacteria at $37^{\circ} \mathrm{C}$ is 19 hours. Methane production also can be suppressed by reduction of $\mathrm{pH}$ below the normal range of 6.8 to 7.5 required by the methanogenic phase (Eastman and Ferguson, 1981).

Guerrero et al. (1999), reported that during primary sludge digestion an initial period between 1-10 days could be observed where hydrolysis - acidification were the controlling processes and very low methane production occurred. Following this initial period, VFA accumulation decreases and methane production becomes more important.

The Anaerobic Digestion model No. 1 (ADM1) (IWA, 2002), is a structured model with disintergration and hydrolysis, acidogenesis, acetogenesis and methanogenesis steps. Extracellurar solubilisation steps are divided into disintergration and hydrolysis, of which the first is a largely non-biological step and converts composite particulate substrate to inerts, particulate carbohydrates, 
proteins and lipids. The second is enzymatic hydrolysis of particulate carbohydrates, proteins and lipids to monosaccharides, aminoacids and long chain fatty acids (LCFA), respectively. Disintergration is mainly included to describe degradation of composite particulate material such as primary or waste activated sludge. The hydrolysis steps are to describe the degradation of well defined macromolecule substrates to each soluble monomer. All disintegration and hydrolysis kinetics are represented by first order kinetics. Two separate groups of acidogens degrade monosaccharide and aminoacids to organic acids, hydrogen and carbon dioxide. The organic acids are subsequently converted to acetate, hydrogen and carbon dioxide by acetogenic groups that utilize LCFA, butyrate and valerate (one microorganism group for both substrates), and propionate. The hydrogen produced by these organisms is consumed by a hydrogen-utilizing methanogenic group, and the acetate by an aceticlastic methanogenic group. Substrate based Monod-type kinetics (slightly different from ASM Monod growth-based kinetics) are used as the basis for all intracellular biochemical reactions. Death of biomass is represented by first order kinetics, and dead biomass is maintained in the system as composite particulate material. Several mechanisms of inhibition are described in the model that includes $\mathrm{pH}$ (all groups), hydrogen (acetogenic groups) and free ammonia (aceticlastic methanogens) inhibition. $\mathrm{pH}$ inhibition is implemented as one of two empirical equations, while hydrogen and free ammonia inhibition are represented by non-competitive functions. The other uptake regulating functions are secondary Monod kinetics for inorganic nitrogen (ammonia and ammonium), to prevent growth when nitrogen is limited, and competitive uptake of butyrate and valerate by the single group that utilizes these two organic acids. Mechanisms included to describe physico-chemical processes are acid-base reactions (to calculate concentrations of hydrogen ions, free ammonia and carbon dioxide), and non-equilibria liquid-gas transfer. Inorganic solids formation and precipitation is not included in the model due to the complexity of the precipitation kinetics and the relatively limited effect on SCOD in acid digesters.

The objective of this work was the application and evaluation of ADM1 for the simulation of anaerobic hydrolysis and acid production processes in primary sludge acid digesters. Model calibration and verification was performed using experimental data from two bench scale acid digesters operating at different temperatures $\left(12,20,27\right.$ and $\left.34^{\circ} \mathrm{C}\right)$ and retention times $(1,2,4$ and $6 \mathrm{~d})$.

\section{Materials and methods}

\subsection{Experimental set up and analytical methods}

Experiments were conducted in two bench scale $5 \mathrm{~L}$ primary sludge acid digestion systems. Each of the reactors operated at a different hydraulic retention time, submerged in a water bath for constant temperature maintenance. The anaerobic hydrolysis of primary sludge was studied at four different temperatures: 12, 20, 27 and $34^{\circ} \mathrm{C}$, and four different HRTs $1,2,4$ and 6 days.
The reactors were operated in a pseudo-continuous flow mechanically stirred-tank mode, without sludge recycling $(H R T=S R T)$. The reactors were fed once a day with primary sludge from a pilot municipal wastewater treatment plant (EYDAP, Research and Development Department). The overall duration of the acid digestion experiments was 8 months. Acid digesters experimental protocol was to operate each digester at constant temeperare for at least 3 HRTs to reach steady state conditions. Thereafter, digester performance was evaluated for at least 10 HRTs before proceeding to the next phase. Every day the following parameters were measured in influent and effluent sludge samples:

- total and volatile solids (TS and VS)

- total and dissolved COD (TCOD and SCOD)

- ammonia nitrogen $\left(\mathrm{NH}_{4}-\mathrm{N}\right)$

Total Kjeldahl Nitrogen (TKN) and volatile fatty acids (VFA) concentrations were also measured in a regular basis. All analyses were conducted according to Standard Methods (1989).

\subsection{Mathematical model}

ADM1 was used for the simulation of the acid digesters operation. All ADM1 biochemical processes and inhibition forms were applied, except from free ammonia inhibition. Due to the low $\mathrm{pH}$ the free ammonia concentration in the prefermenters was low and therefore ammonia inhibition was considered negligible. The equations describing the hydrogen and methane transfer from the liquid to the gas phase were also included:

$\rho_{i}=k_{L} a .\left(S_{i}-16 . K_{H, i} . P_{g a s, i}\right)$

Carbon dioxide was not included in the implementation as it is not necessary for the stages of hydrolysis and acidogenesis simulation. Pgas,i were equal to the partial atmospheric pressure of the gases, as the pilot prefermenters were open.

In a continuous-flow stirred-tank reactor with constant volume $V$, constant inflow and outflow $q$, inflow dissolved and particulate constituents concentrations $S_{i, i n}$ and $X_{i, i n}$ and effluent concentrations $S_{i}$ and $X_{i}$, the mass balance for the dissolved constituents is:

$\frac{d V S_{i}}{d t}=\mathrm{qS}_{\mathrm{i}, \mathrm{in}}-\mathrm{qS}_{\mathrm{i}}+\mathrm{Vr}_{\mathrm{i}} \Rightarrow \frac{\mathrm{dS}}{\mathrm{dt}}=\frac{1}{\mathrm{HRT}}\left(\mathrm{S}_{\mathrm{i}, \mathrm{in}}-\mathrm{S}_{\mathrm{i}}\right)+\mathrm{r}_{\mathrm{i}}$

where $r_{i}$ is the rate of constituent $i$ production due to biochemical and liquid-gas transfer processes. The same equation applies for particulate constituents (SRT = HRT).

The key criticism of structured models to describe biological processes is the large number of parameters employed. In order to evaluate the effect of the various parameters employed on the output of the model, sensitivity analysis was performed for the different model parameters and particularly for:

- Different microorganism groups maximum specific uptake rates

- $\mathrm{pH}$

- disintegration and hydrolysis first order parameters 
- the carbohydrates, proteins and lipids concentration in the feed

- the anaerobic biomass concentration in the feed

- the acid/acetogens and methanogens percentage in this biomass.

\section{Results and discussion}

\subsection{Sensitivity analysis}

Sensitivity analysis was performed in order to evaluate the effects of the various model parameters on the output of ADM1 model.

Table 1. Primary sludge feed characteristics

\begin{tabular}{|c|c|}
\hline Parameter & Value \\
\hline TCOD (mg/l) & 50.000 \\
\hline $\mathrm{SCOD}(\mathrm{mg} / \mathrm{l})$ & 1040 \\
\hline Inert SCOD $S_{i}(\mathrm{mg} / \mathrm{l})$ & $104(10 \%$ SCOD $)$ \\
\hline Inert PCOD Xi $(\mathrm{mg} / \mathrm{l})$ & $2938(6 \%$ PCOD $)$ \\
\hline TKN (mgN/l) & 780 \\
\hline $\mathrm{NH}_{3}-\mathrm{N}(\mathrm{mgN} / \mathrm{l})$ & 110 \\
\hline Biomass (mgCOD/l) & 6.500 (13\% TCOD) \\
\hline Acid/acetogen biomass (mgCOD/l) & 5.850 (90\% biomass) \\
\hline $\begin{array}{c}\text { Sugar }\left(\mathrm{X}_{\mathrm{su}}\right) \text {, amino acid }\left(\mathrm{X}_{\mathrm{aa}}\right), \text { LCFA }\left(\mathrm{X}_{\mathrm{fa}}\right) \text {, valerate and butyrate }\left(\mathrm{X}_{\mathrm{c} 4}\right) \text {, propionate } \\
\text { degraders }\left(\mathrm{X}_{\mathrm{pro}}\right)(\mathrm{mgCOD} / \mathrm{I})\end{array}$ & 1170 (each $18 \%$ of acid/acetogen biomass) \\
\hline Methanogen biomass (mgCOD/l) & 650 (10\% biomass) \\
\hline Aceticlastic $\left(\mathrm{X}_{\mathrm{ac}}\right)$ and hydrogen $\left(\mathrm{X}_{\mathrm{h} 2}\right)$ methanogens (mgCOD/l) & 325 ( $5 \%$ biomass $)$ \\
\hline Butyric acid (mgCOD/l) & 180 \\
\hline Propionic acid (mgCOD/l) & 140 \\
\hline Acetic acid (mgCOD/l) & 90 \\
\hline Sugars $\left(\mathrm{S}_{\mathrm{su}}\right)$, aminoacids $\left(\mathrm{S}_{\mathrm{aa}}\right)$, LCFA $\left(\mathrm{S}_{\mathrm{fa}}\right)$ and valeric acid $\left(\mathrm{S}_{\mathrm{va}}\right)(\mathrm{mgCOD} / \mathrm{l})$ & Each component equal to $\left(\mathrm{SCOD}-\mathrm{VFA}-\mathrm{S}_{\mathrm{i}}\right) / 4=131,5$ \\
\hline Carbohydrates $\left(X_{c h}\right)$, proteins $\left(X_{\text {pr }}\right)$, lipids $\left(X_{\text {li }}\right)(\operatorname{mgCOD} / I)$ & 0 \\
\hline Composite particulates $\mathrm{X}_{\mathrm{C}}(\mathrm{mgCOD} / \mathrm{I})$ & PCOD $-X_{i}-$ biomass $=39.522$ \\
\hline
\end{tabular}

\subsubsection{Substrate maximum specific uptake rates}

The model was solved for three different values of each microorganisms group maximum specific uptake rate: the ADM1 suggested value, $50 \%$ and $200 \%$ of this value (variability 100\%). Especially for the fatty acids uptake rate $25 \%$ and $400 \%$ of the suggested value were also included (variability $400 \%$ ). As it was expected, the value of each specific substrate uptake rate had a significant impact in the relative food concentration (sugars, aminoacids, fatty acids, butyrate, propionate, acetate, hydrogen). These substrate specific uptake rates however (except for acetate uptake rate) proved to have an insignificant effect on the final VFA concentration. On the other hand, as shown in Figure 1, acetate uptake rate exerted a significant impact in SCOD and VFA concentration.

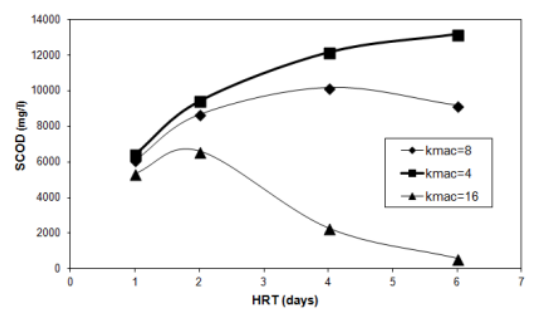

Figure 1. Acetate specific uptake rate effect in SCOD production
The impact of the model parameters on SCOD and especially on VFA production, was examined. The primary sludge feed characteristics used in the model sensitivity feed was taken $13 \%$ of the TCOD as estimated by Munch et al. (1999). The same authors estimated that the portion of acid/acetogens and methanogens in the anaerobic biomass was equal to $90 \%$ and $10 \%$, respectively. The operating digester temperature was $35^{\circ} \mathrm{C}$, because ADM1 model parameters suggested values are set at $35^{\circ} \mathrm{C}$, and $\mathrm{pH}=6.3$. analysis are shown in Table 1 . Anaerobic biomass in the

\subsection{2. $\mathrm{pH}$}

$\mathrm{pH}$ values effect considerably the anaerobic sludge hydrolysis yield. At $\mathrm{pH}$ values of less than 6 , increasing residence time up to 20 days, results in a significant increase in effluent SCOD concentration due to a complete inhibition of methanogenesis. At $\mathrm{pH}$ values greater than 6 , effluent SCOD concentration appears to have a maximum point, at a residence time between 2-4 days. Following that, SCOD concentration decreases with increasing residence time due to methane production (Figure 2).

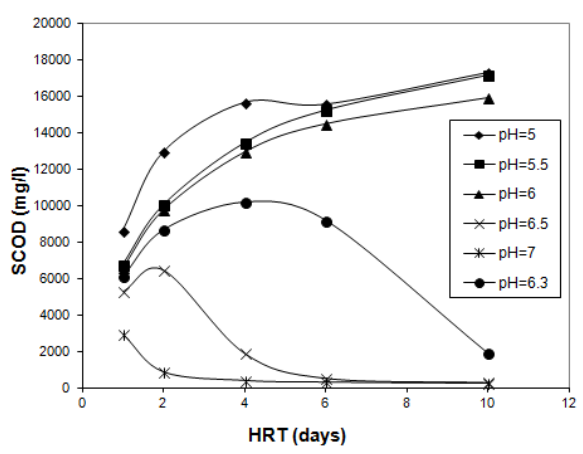

Figure 2. $\mathrm{pH}$ effect in SCOD production 


\subsubsection{Disintegration and hydrolysis kinetic parameters}

The disintegration first order parameter effects the effluent soluble COD concentration more than the respective hydrolysis constant, as according to the model, disintegration is considered the rate limiting step for particulate COD consumption and SCOD production. Therefore although the concentration of the particulate COD fractions (complex particulate, carbohydrate, protein and lipids) varies according to the value of the hydrolysis rate the concentrations of dissolved constituents, that are the final products of particulate substrates, are affected only by the disintegration rate variation.

\subsubsection{Particulate material composition}

Evaluation of the influence of particulate COD fractions (i.e. carbohydrates, proteins, lipids and inert COD) on the effluent SCOD and VFA production is very interesting as their actual measurement is difficult and time consuming. ADM1 task group assumes that primary sludge disintegrates to carbohydrates, lipids, proteins and inert material. The suggested fractions, reported as percent of the total influent COD are $20 \%$ for proteins and carbohydrates, $25 \%$ for lipids $25 \%$ for inert particulate COD and $10 \%$ for dissolved COD. Model sensitivity analysis showed that an increase in lipids from 20 to $45 \%$ of the total COD exerted a minor effect on SCOD and VFA yield. The same increase in proteins and carbohydrates fractions resulted in a small increase and decrease respectively in SCOD production, due to the decrease and increase respectively observed in the amount of methane produced from hydrogen consumption.

\subsubsection{Biomass concentration in primary sludge}

The concentration of each microorganism group in primary sludge is required as an input to the model. Estimation of anaerobic biomass concentration in primary sludge is difficult, and estimation of each microorganisms group concentration is almost impossible. Model sensitivity analysis was conducted for a total anaerobic biomass of $6 \%, 13 \%$ and $26 \%$ of TCOD in the feed and a methanogenic biomass of $10 \%$ and $30 \%$ of total anaerobic biomass. As shown in Table 1, acid/acetogen and methanogen biomass was divided equally among the various microorganism groups. According to sensitivity analysis the influence of biomass composition on SCOD production is very significant, due to the respective variation of available food and methane production. Methanogen biomass increase results in an increased methane production and a subsequent significant decrease in SCOD and VFA production.

\subsection{Model calibration with experimental data}

Preliminary model simulations according to the default values proposed by $A D M 1$, resulted in effluent SCOD concentrations significantly higher than the measured ones. Therefore calibration of the model parameters was attempted in order to obtain a closer agreement to operational results of the two bench scale acid digesters. As described previously anaerobic sludge hydrolysis was studied at four different temperatures: 12, 20, 27 and $34^{\circ} \mathrm{C}$, and four different HRTs 1, 2, 4 and 6 days.
The parameters describing methanogenesis (i.e. specific methanogenesis rate, methanogen biomass concentration in feed and $\mathrm{pH}$ inhibition coefficients) were estimated according to TCOD in the influent and effluent sludge samples. The difference between influent and effluent TCOD concentration was considered equal to methane production as hydrogen production was considered negligible. By SCOD and $\mathrm{NH}_{4}-\mathrm{N}$ fitting, disintegration and hydrolysis parameters were estimated, as $\mathrm{NH}_{4}-\mathrm{N}$ production is affected significantly only from these processes, and SCOD production is influenced by disintegration, hydrolysis and methane production.

During the experiments TCOD, SCOD and VFA (acetic, propionic and butyric acid) concentrations were measured in influent and effluent sludge samples obtained from the two lab scale acid digesters. The various fractions of SCOD were determined as follows: $10 \%$ of SCOD was considered to be inert COD, VFA concentration was set equal to the measured values and the non-VFA SCOD was divided equally to the remaining dissolved constituents of the model: sugars, aminoacids, LCFA and valeric acid. The various fractions of particulate COD (PCOD) were determined as follows: 6\% PCOD was considered to be inert, and the rest PCOD was considered to be composite particulate material and biomass, while pure particulate constituents (carbohydrates, proteins and lipids) were supposed to be negligible. Anaerobic biomass in the feed sludge was $6 \%$ of the TCOD, and $10 \%$ of total anaerobic biomass was supposed to be methanogen. Disintegration of this composite particulate material yields $25 \%$ carbohydrates, proteins, lipids and inert particulate COD. Yield to inert soluble COD was supposed to be zero, as VFA concentration in pilot plant effluent was almost equal with SCOD.

ADM1 default values of various parameters are at $35^{\circ} \mathrm{C}$. The influence of the temperature on the kinetic expressions (uptake rate, Monod and inhibition constants) is assumed to be exponential: $\mathrm{F}(\mathrm{T})=\exp [\theta(\mathrm{T}-35)]$, where $\theta$ is the temperature coefficient. Parameters values in other temperatures were estimated using the temperature coefficients proposed by Siegrist et al. (2002).

Based on the experimental results obtained at $27^{\circ} \mathrm{C}$, an overall TCOD reduction of approximately $20 \%$ was observed in the acid digesters. These results indicate that significant methane production was occurring at $\mathrm{pH}$ values between $5.5-6$. However according to the initial values of $\mathrm{pH}$ inhibition coefficients, proposed by ADM1, negligible methane production should be expected at this low pH range. To simulate more accurately the experimental data $\mathrm{pH}$ inhibition coefficients were decreased to $\mathrm{pHuL}_{\mathrm{L}}=6.5$ and $\mathrm{pH}_{\mathrm{LL}}=5$ from 7 and 6 respectively. Similarly according to the default model parameters there was a significant difference between SCOD concentration measured in effluent sludge samples and model output that tend to increase with increasing residence time. To obtain a closer agreement disintegration and hydrolysis rate were decreased and specific uptake rate from aceticlastic biomass was increased. 


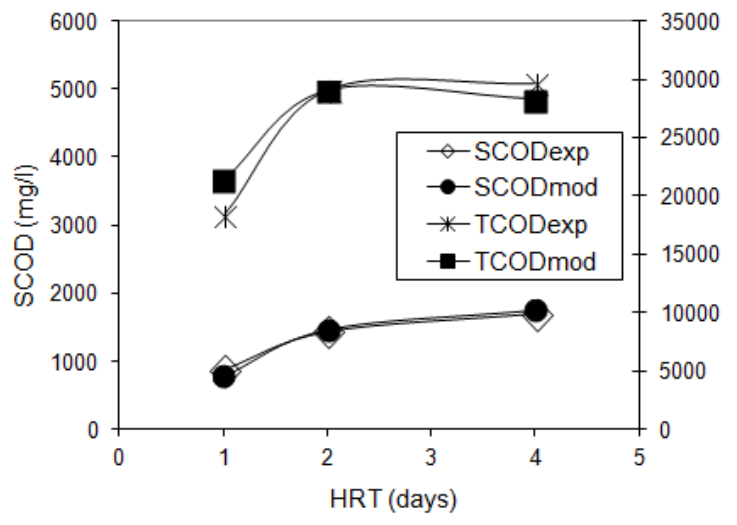

Figure 3. Experimental versus model results at $12^{\circ} \mathrm{C}$

Figures 3-6 illustrate the final results of the model simulation in comparison to the experimental results obtained at different temperatures and residence time. Model simulation is in good agreement with lab scale results especially at operating temperatures of $12^{\circ} \mathrm{C}$ and $20^{\circ} \mathrm{C}$. Model results obtained at $27^{\circ} \mathrm{C}$ and $34^{\circ} \mathrm{C}$ and 4-6 days residence time appear to predict a higher hydrolysis increase compared to experimental data. This difference may be attributed to a higher inert particulate COD content in sludge feed than the one assumed by the model.

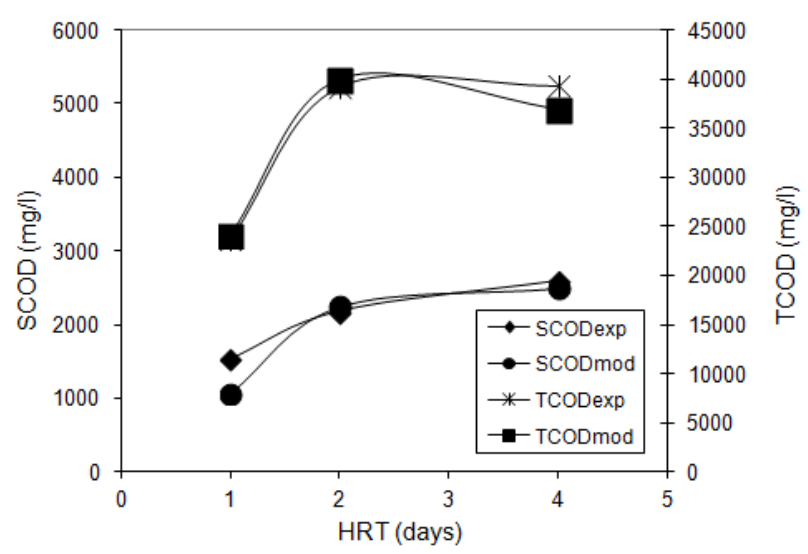

Figure 4. Experimental versus model results at $20^{\circ} \mathrm{C}$

The final values for disintegration and hydrolysis first order parameters and aceticlastic methanogenesis specific uptake rate estimated at various temperatures are shown in Table 2. From these values the following temperature dependence equations were derived:

- $\quad \mathrm{k}_{\mathrm{dis}}(\mathrm{T})=0.32 \exp [0.053(\mathrm{~T}-35)]$

- $\quad k_{\text {hyd }}(T)=6.4 \exp [0.053(T-35)]$

- $\quad k_{m \_a c}(T)=15.7 \exp [0.071(T-35)]$

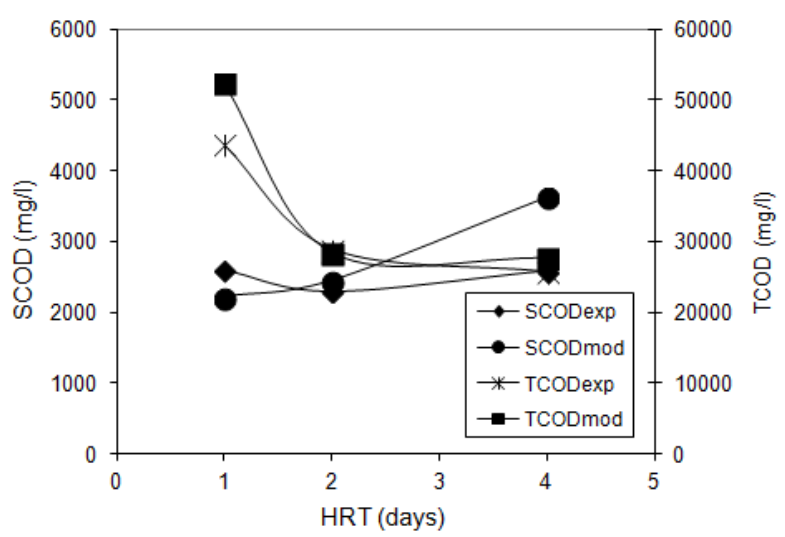

Figure 5. Experimental versus model results at $27^{\circ} \mathrm{C}$

The temperature dependence coefficient for disintegration and hydrolysis was 0.053, a value significantly higher than 0.024 reported by Siegrist et al. (2002), but comparable to 0,054 proposed by Ferreiro et al. (2003) for primary sludge hydrolysis. The temperature dependence coefficient for methanogenesis according to model calibration was equal to 0.071 in good agreement with the values reported by Siegrist et al. $(0,069)$.

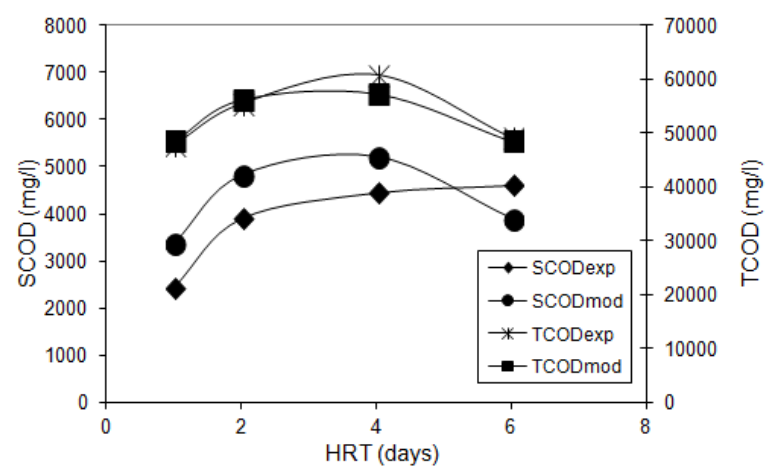

Figure 6. Experimental versus model results at $34^{\circ} \mathrm{C}$

Table 2. Disintegration and hydrolysis first order parameters and aceticlastic methanogenesis specific uptake rate at various temperatures

\begin{tabular}{|c|c|c|c|c|}
\hline Kinetic parameters & $12^{\circ} \mathrm{C}$ & $20^{\circ} \mathrm{C}$ & $27^{\circ} \mathrm{C}$ & $34^{\circ} \mathrm{C}$ \\
\hline Disintegration first order kinetic parameter, $\mathrm{k}_{\mathrm{dis}}\left(\mathrm{d}^{-1}\right)$ & 0,095 & 0,14 & 0,22 & 0,30 \\
\hline Hydrolysis first order kinetic parameter, $k_{\text {hyd }}\left(d^{-1}\right)$ & 1,90 & 2,80 & 4,40 & 6,00 \\
\hline Aceticlastic methanogenesis, $\mathrm{k}_{\mathrm{m}_{\_} a c}\left(\mathrm{~d}^{-1}\right)$ & 3,30 & 4,40 & 10,50 & 14,00 \\
\hline
\end{tabular}


The values of the disintegration and hydrolysis coefficients at $35^{\circ} \mathrm{C}$, obtained according to the model and the experimental results presented in this study $\left(k_{\text {dis }}=0.32\right.$, $k_{\text {hyd }}=6.4$ ) were lower than the ones proposed by ADM1 $\left(k_{\text {dis }}=0.5, k_{\text {hyd }}=10\right)$. This was attributed to the long sludge retention time in the primary settling tank and the consequently high VFA concentration in the influent sludge indicating that fermentation of sludge commenced in the settling tanks. For the same reason the estimated value of aceticlastic methanogenesis parameter $\left(\mathrm{k}_{\mathrm{m}_{-} \mathrm{ac}}=\right.$ 15.7) appeared significantly higher than the default value $\left(k_{m_{a} a c}=8\right)$ proposed by ADM1. The estimated values however are in agreement with the ones reported by Siegrist et al. (2002) khyd $=0.25$ (one step hydrolysis) and $\mathrm{k}_{\mathrm{m} \_\mathrm{ac}}=14.8$.

\section{Conclusions}

ADM1 appears to simulate quite accurately the operation of acid digesters. However a complex problem is the estimation of the values of various substrate components concentrations, kinetic parameters and stoichiometric coefficients.

Model sensitivity analysis showed a significant dependence of the soluble COD and VFA yield from the $\mathrm{pH}$ value, disintegration kinetic parameter and aceticlastic methanogenesis specific rate, as well as biomass and inert soluble COD concentration in primary sludge.

Following calibration, model simulation was in good agreement with lab scale results at operating temperatures in the range from $12^{\circ} \mathrm{C}-34^{\circ} \mathrm{C}$ and residence time from 1-6 days. The values of rate parameters (disintegration and hydrolysis kinetic parameters) as well as their temperature dependence, estimated according to the model were comparable to values reported in the literature. Aceticlastic methanogenesis kinetic parameter according to model calibration was higher than the values reported in the literature. The higher aceticlastic methanogenesis kinetic parameter obtained according to the model was attributed to the long sludge retention time in the primary settling tank.

\section{References}

American Public Health Association, American Water Works Association and Water Environment Federation (1989), Standard Methods for the Examination of Water and Wastewater, 17th ed., Washington, D.C.

Brinch P.P., Rindel K. and Kalb K. (1994), Upgrading to nutrient removal by means of internal carbon from sludge hydrolysis, Water Science \& Technology 29(12), 31-40.

Eastman J.A. and Ferguson J.F. (1981), Solubilization of particulate organic carbon during the acid phase of anaerobic digestion, Journal WPCF, 53(3), 352-366.

Ferreiro N. and Soto M. (2003), Anaerobic hydrolysis of primary sludge: influence of sludge concentration and temperature, Water Science \& Technology 47(12), 239-246.

Guerrero L., Omil F., Mendez R. and Lema J.M. (1999), Anaerobic hydrolysis and acidogenesis of wastewaters from food industries with high content of organic solids and protein. Water Research 33(15), 3281-3290.
IWA Task Group for Mathematical Modelling of Anaerobic Digestion Processes, Anaerobic Digestion Model No. 1. Scientific and Technical Report No. 13, IWA Publishing, 2002.

Munch E.V., Keller J. Lant P. and Newell R. (1999), Mathematical Modelling of Prefermenters - I. Model Development and Verification. Water Science \& Technology 33(12), 2757-2768.

Pitman A.R., Lotter L.H., Alexander V. and Deacon S.L. (1992), Fermentation of raw sludge and elutriation of resultant fatty acids to promote excess biological phosphorus removal. Water Science \& Technology 25(4-5), 185-194.

Siegrist H., Vogt D., Garcia-Heras J., and Gujer W. (2002), Mathematical Model for Meso- and Thermophilic Anaerobic Sewage Sludge Digestion. Environmental Science \& Technology 36, 1113-1123. 